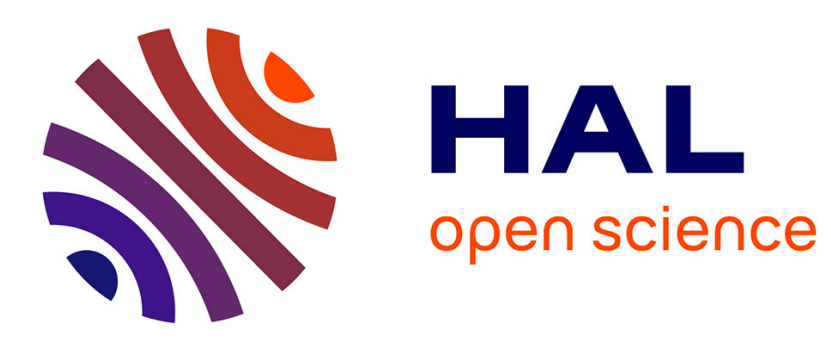

\title{
Introducing carbon constraint in the steel sector: ULCOS scenarios and economic modeling
}

Elie Bellevrat, Philippe Menanteau

\section{To cite this version:}

Elie Bellevrat, Philippe Menanteau. Introducing carbon constraint in the steel sector: ULCOS scenarios and economic modeling. Revue de Métallurgie, 2009, 9, pp.318-324. 10.1051/metal/2009059 . halshs-00430381

\section{HAL Id: halshs-00430381 https://shs.hal.science/halshs-00430381}

Submitted on 6 Nov 2009

HAL is a multi-disciplinary open access archive for the deposit and dissemination of scientific research documents, whether they are published or not. The documents may come from teaching and research institutions in France or abroad, or from public or private research centers.
L'archive ouverte pluridisciplinaire HAL, est destinée au dépôt et à la diffusion de documents scientifiques de niveau recherche, publiés ou non, émanant des établissements d'enseignement et de recherche français ou étrangers, des laboratoires publics ou privés. 


\title{
Introducing carbon constraint in the steel sector : ULCOS scenarios and economic modeling
}

\author{
Elie Bellevrat ${ }^{1}$ and Philippe Menanteau ${ }^{2}$ \\ ${ }^{1}$ Enerdata, Grenoble, France \& ${ }^{2}$ LEPII-EPE (CNRS), Grenoble, France \\ elie.bellevrat@enerdata.fr
}

\begin{abstract}
Modeling activities and scenario building are at the heart of the economic analysis delivered by the ULCOS program. Two main objectives were followed in the framework of SP9. First the modeling team had to provide a set of coherent energy economic scenarios using POLES model. Second, the economic conditions for the emergence of the ULCOS technologies were analyzed. ULCOS contributes to the elaboration of contrasted scenarios that the steel industry could face in the long term. To aim at these objectives specific tools have been used: POLES model for the global energy system modeling and ISIM model for the steel sector based prospective ([1] Hidalgo, 2003). The most promising steel production technologies identified in ULCOS Phase 1 have been introduced into ISIM as generic technologies. ISIM was then integrated as a module into POLES modeling system. The main model outputs are the energy prices and mixes and the steel sector balances with a focus on the technology mix. Actually the climate policy scenarios developped in project allow making recommendations to the steel industry in terms of sustainable development but also in terms of business strategy.
\end{abstract}

\section{Introduction}

The aim of the ULCOS research program is to identify the ultra low $\mathrm{CO}_{2}$ steel production technologies that should be implemented by the steel industry in the framework of the ambitious European climate policies.

The objective of this work programme on Scenario and Economic Modeling was to provide ULCOS partners with a set of consistent economic scenarios under various future climate regimes, among which highly constrained carbon futures either on a unilateral (European) or a cooperative (World) basis.

Economic modeling of the world energy system has been used to estimate future international energy prices and carbon constraints (1st phase) and the impact of climate policy on the steel sector and on the evolution of the technology mix (2nd phase).

The simulation of the world energy system development up to 2050 has been carried out with the POLES partial equilibrium model that was developed at LEPII. A steel module (ISIM model) developed by IPTS has also been added to the POLES modeling system in order to provide an accurate description of the steel sector

In this paper we will first quickly describe the modeling system that has been used for this simulation, the steel technologies that we considered and the different scenarios that we have elaborated. We will then present the main results of the simulation for the different scenarios on the global steel demand, the technology mix and the evolution of the European steel production.

\section{Economic modeling}

Economic modeling is now systematically used by policy makers to elaborate energy or climate change policies ([2] EC, 2006)). These scenarios can be helpful to industrial sectors to elaborate their long term strategies in an uncertain world. Electric utilities and energy intensive industries have a long experience in energy modeling.

Several arguments explain why energy intensive industries are more and more interested in energy and environment prospective exercises. First, modeling can help them assessing the economic impact of future energy and climate regulations. Estimating the carbon price resulting from the evolution of the rules in the ETS (European Trading System) in Europe for example is a central issue for cement, aluminum or steel industry ([3] Demailly, 2007 and [4] Hidalgo, 2005). Second, it is essential for them to study the evolution of fundamental economic parameters in order to assess the appropriate innovation strategies and the possible role of radical innovation technologies. And third, resources and their localization will also have a deep impact on the future energy prices and as a consequence, on today's industrial choices.

In the next decades, inter-technology competition (and the resulting merit-order) will take place in a much more complex set of economic fundamentals, among which energy prices. However, not all the combinations are possible and simulation or sectoral equilibrium models can help in identifying consistent sets of hypothesis for technology (and investment) planning.

Because the steel industry was convinced by the interest of this issue, energy and environment modeling has been introduced from the beginning as a key topic into the ULCOS program. Former exercises 
did exist but they usually studied the impact of short term constraints on incremental innovation ([5] Gielen, 2002 and [6] Daniëls, 2001). Economic modeling of the world energy system is here used to estimate international energy prices and carbon constraint scenarios. The impact of climate policy on the steel sector and the evolution of the technology mix are analyzed through a partial equilibrium modeling system. The simulations have been carried out with the POLES model including a specific steel submodule (ISIM) developed during the IDDRI-EPE project.

\section{i. POLES model}

POLES has been developed since the 90 's by the economist Patrick Criqui, who is now director of the LEPII, a research laboratory on industrial economics of the French National Research Center (CNRS). This model is used at the European level (WETO-H2 and ADAM projects for the DG Research of the European Commission) and at the national level (French or British Ministries for Environment), but also by industrials (EDF, Statoil, for example) in order to explore the options for technology and climate policies in the next half-century.

POLES is a global model that divides the world in 47 countries/regions and projects annual energy balances for each of them. Fifteen consuming sectors and the whole energy sources and energy carriers are represented. In POLES, the price of final energies is an output that depends on complex and dynamic interactions between resource availability (for oil and gas) and climate and energy policies $([7,8,9]$ Rynikiewicz, 2005, 2007 and 2008).

\section{ii. ISI M model}

ISIM is a steel-sector based simulation model with explicit technologies. The inter-technology competition module represents both the greenfield and brownfield capacity planning. It has been developed at the Joint Research Center of the European Commission at Seville by Hidalgo et al. ([1,4] IPTS, 2003 and Hidalgo, 2005).

\section{Techno-economic database}

\section{i. TECHPOL database}

The TECHPOL data format is designed to feed the POLES modeling system with detailed economic and technical information on the main production technologies ([10] Menanteau, 2006). The database provides both observed and prospective technicoeconomic data at medium and long term horizons (2025 and 2050). The technico-economic data on steel production technologies that are used in the POLES model have been updated using the results of ULCOS Phase 1 . The most promising ULCOS technologies have been selected and their costs and performances data integrated into the TECHPOL database.
Standard technologies are also integrated into the TECHPOL database. Three standard technologies are detailed in TECHPOL:

- the Reference Blast Furnace plus oxygen converter (BFR)

- $\quad$ the reference Direct Reduction Process plus electric furnace (DRP)

- $\quad$ the Electric Arc Furnace (EAF)

The old Open Hearth Furnace technology is still represented in some regions (mainly in Central Independent States) but it is quickly decommissioned in the model given its economic performance.

The ULCOS program also helped refine the database format and the various assumptions concerning costs and performances.

\section{ii. ULCOS technologies}

The so-called ULCOS technologies have been assessed in the various Sub Projects from the beginning of the project. Generic technologies were selected from Phase 1 because they were considered as promising, both in terms of economic profitability and environmental performance. They can be divided in two categories: the advanced existing routes (three technologies) that are incremental improvements of existing technologies and the breakthrough technologies (three routes) that are totally new technologies or radical innovations. The advanced existing technologies are:

- the Advanced Blast Furnace with oxygen injection and carbon capture and storage (CCS)

- the Biomass advance Blast Furnace with $50 \%$ charcoal use (BFB)

- $\quad$ the Advanced Direct Reduction process with CCS (DRA)

The breakthrough technologies, which are not supposed to be implemented before 2025-2030 are the following:

- the Smelting Reduction Process (ISARNA type) with CCS (SRP)

- the Alkaline Electrolysis on-grid or with dedicated nuclear electricity (ELA and ELB)

- $\quad$ the Electrolysis High Temperature (EHT)

\section{Scenarios}

In order to represent a broad range of possible future environmental policies, three main scenarios were developed in the second phase of the project.

The Reference scenario follows existing economic and technological trends based on on-going policies for $\mathrm{CO}_{2}$ emissions mitigation. This is reflected in a low carbon value reaching $30 € / \mathrm{tCO}_{2}$ in 2050. As a consequence, the global emissions are multiplied by a factor 2.5 by 2050 compared to 2000 . Emissions from the steel industry reach a ceiling in 2030. Clear- 
ly, this scenario is not sustainable from the climate change point of view but it is used to estimate the impact of more stringent policies.

The $\boldsymbol{F 2}$ World scenario corresponds to a carbon constrained scenario with a reduction of emissions by a factor 2 at the world level in 2050 and a factor 4 for Europe (i.e. a long term stabilization of the GHG concentration at $450 \mathrm{ppm} \mathrm{CO}_{2} \mathrm{eq}$ ). In this scenario, the carbon value reaches the level of $600 € / \mathrm{tCO}_{2}$ in 2050. A variant of this scenario with differentiated carbon values among sectors has been simulated. In this case, the tax level is only $300 € / \mathrm{tCO}_{2}$ in 2050 for industry. The two variants of the scenario lead to very similar global $\mathrm{CO}_{2}$ emissions. The steel sector emissions are cut by approximately a factor 4 in both of them, with a 5 year delay only for the Diff CV variant (see Figure 1 below).

The F2 Europe scenario corresponds to a lower constrained carbon scenario with a reduction of emissions by a factor 2 at the European level in 2050. In this scenario, carbon values were differentiated among sectors, with a resulting level of $110 € / \mathrm{tCO}_{2}$ for the industry in 2050. This scenario with limited constraints in the rest of the world reflects a situation of unilateral action of Europe against climate change.

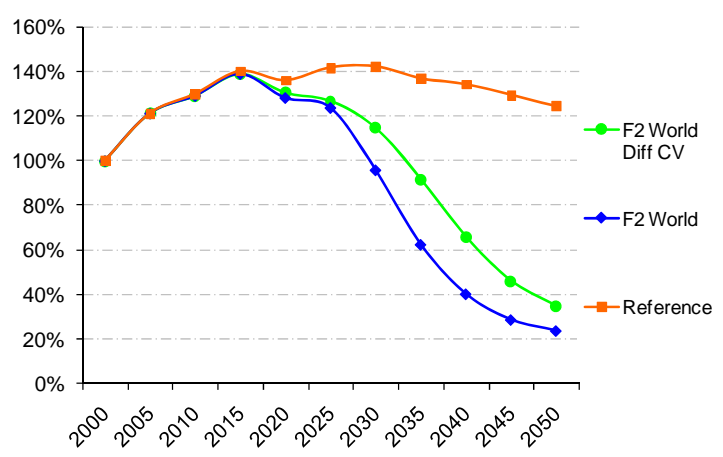

Figure 1. World steel $\mathrm{CO}_{2}$ emissions in the Reference and F2 World scenarios

The F2 World and F2 Europe scenarios exist in "Diff CV" version which means they are based on differentiated carbon constraints among sectors.

Economic theory would recommend a homogeneous carbon tax in all sectors in order to reach economic optimum (i.e. a Pigovian tax). But in this case the carbon cost may not be incentive enough in some sectors (e.g. transport sector) and unbearable for others (e.g. industry and particularly steel industry). Indeed, the Marginal Abatement Cost Curves (MACCS) show that the marginal cost for a given $\mathrm{CO}_{2}$ reduction can be very different from one sector to another (see Figure 2). The issue of a differentiated tax across sectors had been raised several years ago ([11] Hoel, 1996), but not implemented yet. It appeared relevant in the framework of the ULCOS Program to test again this idea with the aim of sending a homogeneous price signal to each sector. The dynamic of introducing these taxes is illustrated with the linear carbon constraint of Figure 3 ([12] Criqui, Grandjean, 2006).

\section{Results}

\section{i. Energy mix}

In the Reference scenario, the consumption of the world energy system doubles in 40 years to reach around $1100 \mathrm{EJ} / \mathrm{yr}$ in 2050. The EU27 primary energy consumption reaches $100 \mathrm{EJ} / \mathrm{yr}$ in 2050 (from around $75 \mathrm{EJ}$ today). In the very constrained case (F2 World scenario), the global primary consumption reaches a ceiling by 2050 (around $650 \mathrm{EJ} / \mathrm{yr}$ ), whereas the EU27 consumption peaks in 2010 at around $80 \mathrm{EJ} / \mathrm{yr}$ and then decreases to $60 \mathrm{EJ} / \mathrm{yr}$ in 2050. The share of fossil fuel into the energy mix is dropping in this scenario.

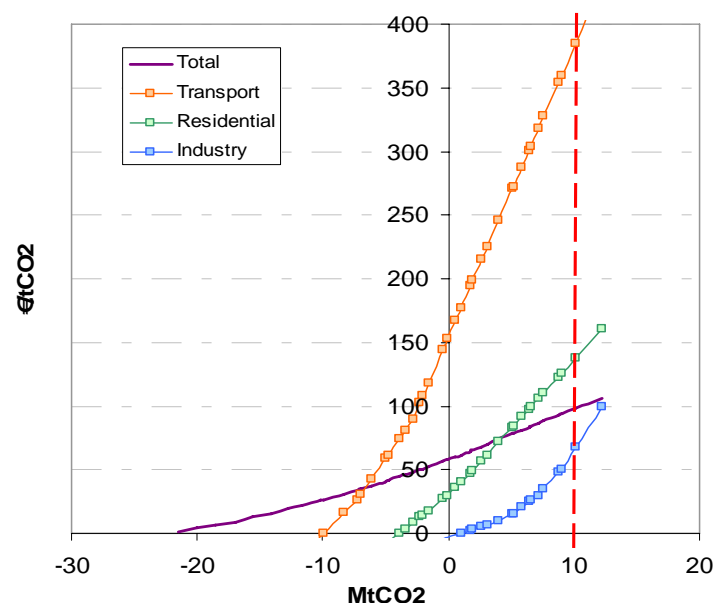

Figure 2. Marginal cost curves of $\mathrm{CO}_{2}$ reduction (France 2020 reductions / 2001) (Source: POLES, 2006)

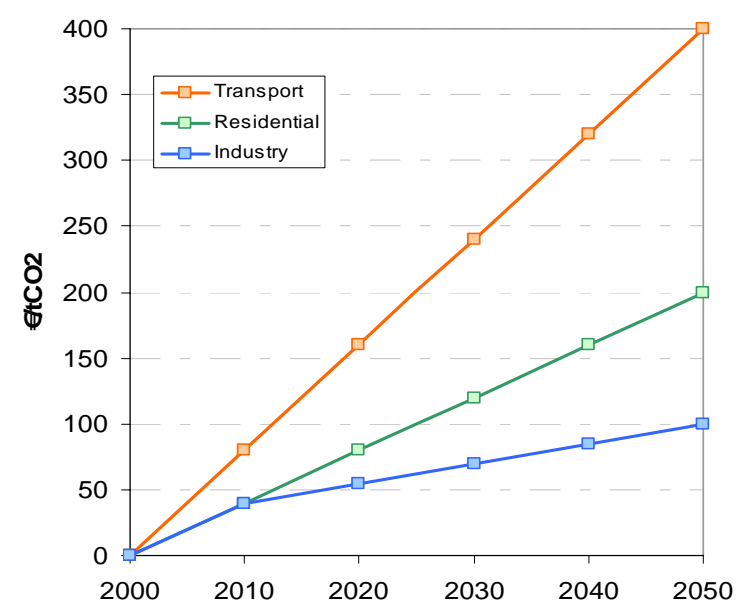

Figure 3. Possible introduction profiles for the carbon constraint (Source: Criqui, Grandjean, 2006)

Energy mixes are deeply impacted by high carbon values. In carbon constrained scenarios, the share of non-emitting electricity sources (renewables and nuclear) increases while the share of electricity produced from fossil fuels decreases. As an example, coal generation drops from almost $25 \%$ in the Reference scenario to $5 \%$ in the F2 World scenario in 
2050 , even taking into account $\mathrm{CO}_{2}$ capture. By 2050 the share of nuclear plus renewable accounts for almost $70 \%$ of the total electricity production in the carbon constrained scenarios (F2 World), instead of $50 \%$ in the Reference scenario. The increase between the scenarios is quite the same for both the energy sources ( $10 \%$ each).

\section{ii. Energy prices}

One of the key outputs of the POLES model is the evolution of international energy prices in the various scenarios. After the peak of 2007-2008 (data have been updated only up to 2006), the international prices of oil and gas would reach a new equilibrium between 2010 and 2015, reflecting the economic fundamentals between global demand and supply in the model (see Figure 4). After this transition period, oil prices are growing again in the reference scenario to reach $140 \$$ /boe in 2050 . Conversely, the oil price remains at a low level of $70 \$ /$ boe from 2025 to 2050 in the very constrained scenarios (F2 World family scenarios) because of the decrease in the global demand (demand is impacted because the final consumer pays the international price plus the carbon tax). In the F2 Europe scenario the impact of a lower demand in Europe is hardly perceptible on the global markets and the international price remains similar to the Reference scenario.

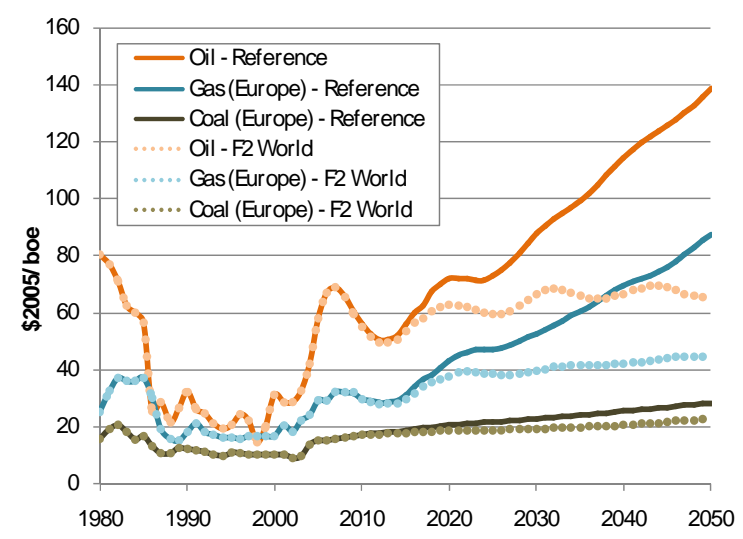

Figure 4. International energy prices for the Reference and F2 scenarios

\section{iii. World steel demand}

In the POLES model the global demand for steel is split into three sectors, namely transport, buildings and "other sectors". The steel demand is simulated in the former sectors according to their respective sectoral activity variables. Transport demand is directly linked to the production of new cars, whereas building demand is linked to the construction of new buildings. The demand in "other sectors" is based on the intensity of use approach that links steel consumption per capita and GDP per capita ([13] Mima, 2006).

Resulting simulation of global steel demand shows a doubling by 2050 to reach around $2200 \mathrm{Mt} / \mathrm{yr}$ in 2050 (This represents a yearly average growth rate of $1.35 \% / y r$. The most important increase comes from the "other sector" as a direct result of GDP per capita increase in our economic assumptions (Figure $5)$. Up to 2025, most of the demand growth comes from China (in the building sector) as a continuation of the on-going trend (Figure 6). In the second half of the period, India takes over from China with a major part of growth caused by increasing demand for mobility at world level.

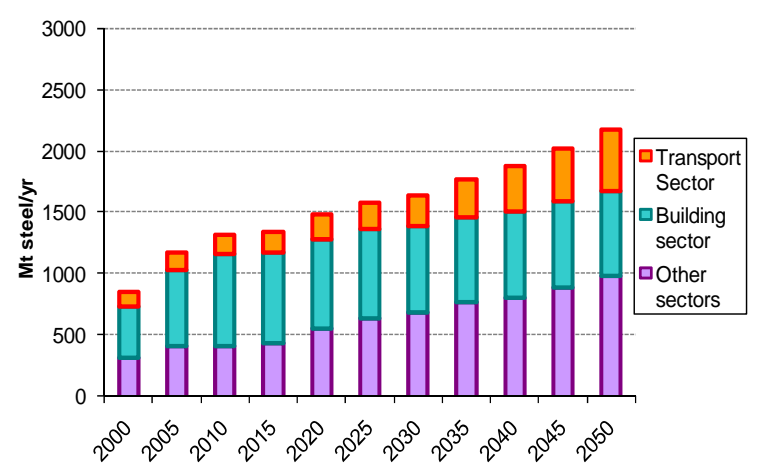

Figure 5. World steel consumption in the Reference scenario, by sector

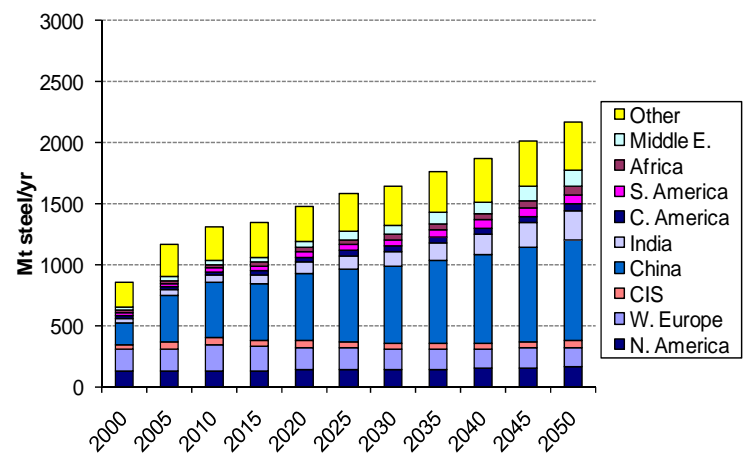

Figure 6. World steel consumption in the Reference scenario, by region

The global steel demand is very sensitive to the hypothesis of economic growth in China. On the assumption of a very high economic growth in China $18.4 \%$ in $2015,4.6 \%$ in 2030 and $3.1 \%$ in 2050 against $5.7 \%$ in $2015,3.3 \%$ in 2030 and $2.4 \%$ in 2050 in the Reference case), global demand could be $400 \mathrm{Mt}$ higher by 2050. In this case the total demand would exceed $2500 \mathrm{Mt} / \mathrm{yr}$ by 2050 . This is a doubling of the global steel demand in 40 years, which represents a yearly average growth rate of $1.75 \% / y r$. In such a scenario, the demand in China would be nearly half of the global demand (around $1200 \mathrm{Mt} / \mathrm{yr}$ in 2050).

In the IEA scenarios ([14] Gielen, 2006), global steel demand projection in 2050 is $1600 \mathrm{Mt} / \mathrm{yr}$ in the low scenario and $2200 \mathrm{Mt} / \mathrm{yr}$ in the high scenario, which is the same order of magnitude as in the POLES reference case.

\section{iv. Technology mix}

The global steel production mix is greatly impacted by the introduction of a carbon tax with different shares of ULCOS technologies according to the scenarios. Figure 7 shows the world steel production mix is in the Reference scenario. In this scenario, the 
Blast Furnace route decreases from nearly $70 \%$ market share in 2005 to $40 \%$ in 2050 . The market share of Direct Reduction from gas gains $10 \%$ in 50 years. Global market share of Electric Arc remains the same over the period (around 35\%), with a minimum in 2025. At the end of the period, breakthrough technologies such as Smelting Reduction and Electrolysis (mainly based on dedicated nuclear electricity) become competitive and reach $10 \%$ market share on the whole.

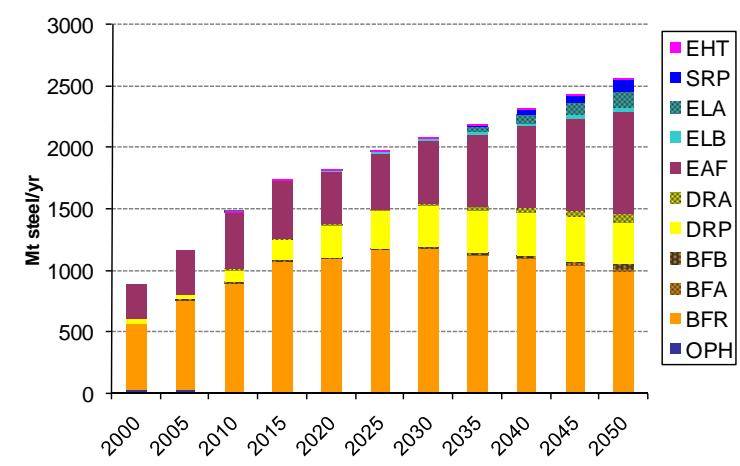

Figure 7. World steel production by technology in the Reference scenario

In the F2 World and in the F2 World with differentiated carbon values (F2 World Diff) scenarios, the diffusion of ULCOS technologies is similar but as stressed before, this result is obtained with half the level of carbon constraint in the steel sector (see Figure 8 for the steel production mix in the F2 World scenario). In F2 World scenarios, the market share of the Blast Furnace route (BFR, BFA, BFB) is comparable to the one in the Reference scenario but the difference comes from the diffusion of advanced blast furnace technologies (BFA and BFB). The reference blast furnace (BFR) is progressively substituted by advanced technologies after 2025 with BFA having 10\% market share by 2050 and BFB having almost $20 \%$. The global share of the blast furnace route remains unchanged because of the retrofitting process between current and advanced capacities, but in the end the market share of the reference blast furnace is less than $5 \%$ in both scenarios.

The evolution is similar for the Direct Reduction route, in which the advanced direct reduction technology (DRA) substitutes the reference direct reduction technology (DRP). The process is not as important as it is for the BF route because the DR route is less carbon intensive. This substitution of DRP by DRA is similar but slightly less marked in the differentiated CV scenario.

Even in highly constrained scenarios, breakthrough technologies for steel production do not take the lead in the long term compared to incremental technologies (advanced blast furnaces and advanced DRI). This is mainly due to the retrofitting option introduced in the model that allows building brownfield advanced blast furnaces more quickly than building greenfield capacities of completely new routes. As a consequence, it is to some extend cheaper to adapt existing production capacities to the environmental constraint than to build greenfield production capacities.

Whatever the investment cost is for electrolysis and smelting reduction routes, the technological diffusion remains low, except in the few regions where the need for greenfield capacities is pulled by high demand such as in developing countries.

No significant evolution of market share is observable in the different scenarios for the Electric Arc Furnace route because almost all scrap available is used on each market and each scenario. It is worth noting that steel production from scrap increases significantly increased availability of recycled steel from 2030 to 2050.

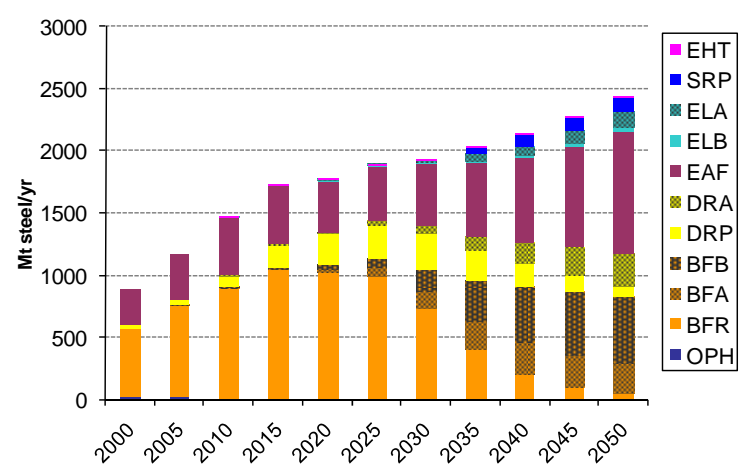

Figure 8. World steel production by technology in the F2 World scenario

According to the results of the model, the loss of production in Europe could be significant as a consequence of the introduction of ambitious climate policies. Paradoxically, the effect could be more pronounced in the F2 World Diff CV scenario compared to the F2 Europe scenario in the short term.

Production loss increases steadily in the F2 Europe Diff CV scenario with a final production loss of $20 \%$ compared to the Reference scenario. In the F2 World Diff CV scenario, the early and strong introduction of a high carbon value in Europe implies a quick loss of production compared to the Reference scenario (up to $30 \%$ ). Then the production loss could decrease to reach less than $5 \%$ by 2050 .

In the F2 World Diff scenario, the gap between European and non-European environmental constraints is more important because Europe implements very early strong climate regulations when other regions have a time delay before setting a strong carbon value. In the case of unilateral action (the F2 Europe scenario), the gap between European and nonEuropean environmental constraints is lower even if Europe "only" has to reach a factor 2 trajectory.

In the long term, leakage grows in the F2 Europe scenario due to the increasing carbon constraint (other regions are always constraint free). On the contrary, in the F2 world scenario the leakage decreases because the gap in carbon value between Europe and the other regions decreases (see Figure 9 for the European steel production in the various scenarios). Moreover, Europe acquires a competitive 
advantage by developing advanced technologies which provides it a production structure that is less sensitive to strong carbon constraint compared to other regions. In the long term the European steel industry could take advantage of the high constraint it suffered in the short term. At this stage, it is important to stress that this modeling result may underestimate real investment decision that could prevent the construction of new production capacities in Europe after a first relocation in emerging countries.

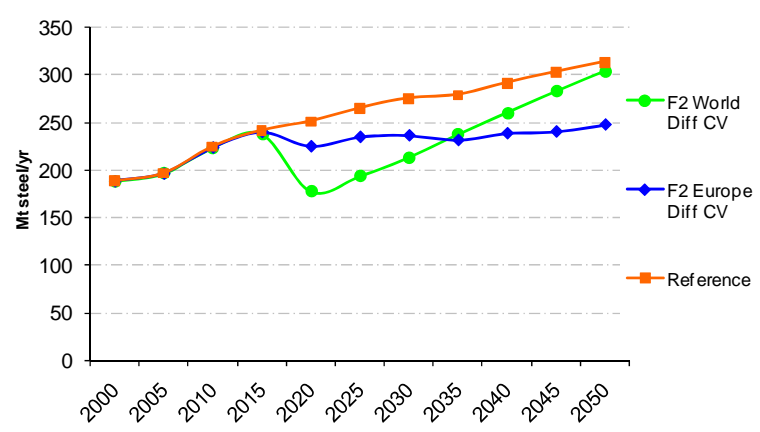

Figure 9. European steel production in three scenarios

\section{Conclusion}

The implementation of ambitious climate policies will deeply impact energy intensive industries, and particularly the steel production industry, with carbon values exceeding $500 € / \mathrm{tCO}_{2}$ in 2050 in order to be compatible with factor 4 emissions reduction scenarios.

In such a carbon constrained world, the steel production mix is deeply impacted with an increasing share of low $\mathrm{CO}_{2}$ emitting technologies. Because of the importance of retrofitting in the model, advanced existing routes (Blast Furnace and Direct Reduction routes) dominate the technology mix but breakthrough technologies emerge in highly carbon constrained scenarios at the 2050 time horizon.

The localization of production capacities can also be affected by ambitious climate policies especially in the case of differentiated constraints among world regions. In the short term, the European steel industry could face loss of production, i.e. delocalization, in scenarios with an important gap between carbon values among Europe and the rest of the world. In the long term, this disequilibrium could be compensated by an early development of ULCOS technologies in the European steel industry.

\section{Acknowledgements}

The present work is part of the ULCOS program, which operates with direct financing from its 48 partners, especially of its core members (ArcelorMittal, Corus, TKS, Riva, Voestalpine, LKAB, Saarstahl, Dillinger Hütte, SSAB, Ruukki and Statoil), and has received grants from the European Commission under the $6^{\text {th }}$ Framework RTD program and the RFCS program $^{1}$.

The authors would like to thank their IPTS modeling partners, Spyridon Merkourakis and Ignacio Hidalgo, for their work on the steel module ISIM. A special thank to the POLES team at LEPII-EREN and Enerdata for their constant help and expertise for new modeling development and for economic analysis.

The research work was made possible thanks to the continuous dialogue with ARCELORMITTAL, and especially with Jean-Pierre Birat. The authors also thank the ULCOS SP9 partners for their critical reviewing of the results.

All the responsibility for the content rests with the authors.

\section{References}

[1] Hidalgo, I. et al. (2003). Energy consumption and CO2 emissions from the world iron and steel industry. JRC-IPTS. EUR 20686 EN

[2] EC. (2006). WETO-H2. World Energy Technology Outlook 2050.

ftp://ftp.cordis.europa.eu/pub/fp7/energy/docs/wetoh2_en.pdf

[3] Demailly, D., Quirion, P. (2007). European Emission Trading Scheme and competitiveness: A case study on the iron and steel industry. Energy Economics doi:10.1016/j.eneco.2007.01.020

[4] Hidalgo, I., Szabo, L., Ciscar, J.C., Soria, A. (2005). Technological prospects and $\mathrm{CO} 2$ emission trading analyses in the iron and steel industry: A global model. Energy 30, 583-610.

[5] Gielen, D., Moriguchi, Y. (2002). CO2 in the iron and steel industry: an analysis of Japanese emission reduction potentials. Energy Policy 30, 849-863.

[6] Daniëls, B. Moll, H. (2001). Integrated energy and materials systems engineering for GHG emission mitigation. MATTER project. ECN Policy studies report. Part 2. Chapter 4. Iron and Steel.

[7] Rynikiewicz, C. (2005). Transitions for radical changes in the European steel industry. 10th European roundtable on sustainable consumption and production. Antwerp, Belgium. 5-7 October 2005.

[8] Rynikiewicz, C. (2007). Contrainte d'environnement global et changement technique induit : vers des trajectoires d'innovation radicales dans la sidérurgie. Thèse de doctorat.

[9] Rynikiewicz, C. (2008). The climate change challenge and transitions for radical changes in the European steel industry. Journal of Cleaner Production 16, 781-789.

[10] Menanteau P. (2006). Techpol, un observatoire des nouvelles technologies de l'énergie. Lettre Techniques de $I^{\prime \prime I n g e ́ n i e u r ~-~ E n e r g i e s, ~} n^{\circ} 2$, p. 5-6

[11] Hoel M. (1996). Should a carbon tax be differentiated across sectors? Journal of Public Economics 59, 17-32.

${ }^{1}$ Priority 3 of the $6^{\text {th }}$ Framework Programme in the area of "Very low $\mathrm{CO}_{2}$ Steel Processes", in co-ordination with the 2003 and 2004 calls of the Research Fund for Coal and Steel 


\section{ulces}

[12] Criqui P. Grandjean, A. (2006). Environnement global: pour une Taxe de Lutte contre le Changement Climatique (TLCC). Working paper LEPII-EPE. http://webu2.upmfgrenoble.fr/iepe/textes/PC-AG_TLCCoct2006.pdf (access 03.07.07)

[13] Mima, S. Rynikiewicz, C. (2006). Preliminary simulations of the Steel Industry facing different carbon constraints. ULCOS Seminar. 16-17 October 2006. Grenoble.

[14] Gielen, D. Podkanski, J. (2006). Technological Potentials for $\mathrm{CO} 2$ Emission Reduction in the Global Iron and Steel Industry. IEA presentation. 2 March 2006. Sydney.

[15] Oda, J. et al. (2007). Diffusion of energy efficient technologies and $\mathrm{CO} 2$ emission reductions in iron and steel sector. Energy Economics 29, 868-888.

[16] ESTP. (2004). European Steel Technology Platform Vision 2030.

[17] EUROFER. (2007). Combating Climate Change. European Confederation of iron and Steel Industries.

[18] IISI. (2005). Steel statistical Yearbook 2005. International I ron and Steel Institute.

http://www.worldsteel.org/2005 (access 15.01.06).

[19] OECD. (2005). Can transnational sectoral agreements help reduce greenhouse gas emissions? Round Table on Sustainable Development. SG/SD/RT(2005)1. 